\title{
Corrosion and Wear Performance of Titanium and Cobalt Chromium Molybdenum Alloys Coated with Dicationic Imidazolium-Based Ionic Liquids
}

\author{
Danyal A. Siddiqui ${ }^{1}$ ' Izabelle M. Gindri ${ }^{1}$ - Danieli C. Rodrigues ${ }^{1}$
}

Received: 11 August 2016/Revised: 9 September 2016/Accepted: 19 September 2016/Published online: 28 September 2016

(c) Springer International Publishing Switzerland 2016

\begin{abstract}
The present work investigates the corrosion and wear performance of titanium (Ti6Al4V) and cobalt chromium molybdenum (Co28Cr6Mo) alloys when coated with dicationic imidazolium-based ionic liquids (ILs). As novel, multi-functional compounds, ILs were assessed in terms of coating stability and ability to enhance corrosion resistance and mitigate wear. The IL with the amino acid, phenylalanine, as the anionic moiety was found to maintain stable coatings on both alloy surfaces in phosphate buffered saline (PBS) at $37{ }^{\circ} \mathrm{C}$ which lowered corrosion rates in comparison to control specimens. However, ILs with bis(trifluoromethylsulfonyl)imide $\left(\mathrm{NTf}_{2}\right)$ as the anion were found to form unstable coatings on both alloy surfaces that eventually dissolved into PBS, resulting in corrosion behavior similar to or worse than that exhibited by control specimens. Although all IL-coated alloy surfaces exhibited lower coefficient of friction (COF) values and smaller wear scars relative to control specimens lubricated with PBS, the IL with phenylalanine occasionally underwent coating exhaustion and was slower to reach stable COF values. Overall, the anionic moiety and alkyl chain length of an IL were observed as key properties that influence adsorption onto a given substrate which in turn influence its performance as an anti-corrosive agent and lubricant. This study highlights the need for careful selection of ILs based on their chemical structure and nature of the coating substrate
\end{abstract}

Electronic supplementary material The online version of this article (doi:10.1007/s40735-016-0057-9) contains supplementary material, which is available to authorized users.

Danieli C. Rodrigues

dxb127430@utdallas.edu

1 Department of Bioengineering, University of Texas at Dallas, Richardson, TX 75080, USA (i.e., surface functional groups) in order to form protective films on biomedical alloys that can improve their corrosion and wear resistance.

Keywords Titanium alloy · Cobalt chromium · Ionic liquids · Corrosion · Wear · Metallic coatings

\section{Introduction}

Biomedical alloys have been widely employed in various implantable devices including dental implants, total joint replacements, cardiovascular stents, pacemakers, and bone fracture fixation devices which all require excellent corrosion resistance [1]. Corrosion resistance can be defined as the ability of a material, usually a metal, to resist chemical degradation due to reactions occurring on its surface which depend on a multitude of factors such as $\mathrm{pH}$, temperature, and nature of the chemical species in the surrounding environment [2]. In air and aqueous environments where oxygen is present, common biomedical alloys like titanium and cobalt chromium exhibit excellent corrosion resistance due to the spontaneous formation of titanium oxide [3] $\left(\mathrm{TiO}_{2}\right)$ and chromium oxide [4] $\left(\mathrm{Cr}_{2} \mathrm{O}_{3}\right)$ on their surfaces, respectively. Passive oxide layer formation is the result of a dynamic electrochemical equilibrium process between oxidation and reduction reactions occurring on the metal surface [5]. This passive layer impedes corrosion, preventing dissolution of metal ions and shielding the bulk metal from the surrounding environment [5].

Although these metal oxide layers are formed and can readily be restored under normal circumstances, in vivo conditions can not only damage the oxide layer but prevent its reformation $[6,7]$. For instance, micromotion can occur between the contacting surfaces of the modular 
components of an implant as a result of applied cyclical loading, which can mechanically wear away the oxide layer in a mechanism known as fretting corrosion [8]. Furthermore, the formation of crevices between these modular components can result in localized corrosion attack due to stagnant fluid accumulation resulting in oxygen depletion and generation of acidic conditions [9]. Additionally, biological factors such as the host tissue response mediated by inflammatory cells or bacterial biofilm formation surrounding implant surfaces are capable of enhancing corrosion processes in vivo $[6,10]$. The combination of mechanical damage and corrosion results in accelerated and often permanent damage to the oxide layer [11], resulting in increased levels of metal ion dissolution [12]. Metal ions released from the metallic surface of an implant can accumulate in surrounding tissues [13] which has been associated with an array of problems ranging from prolonged inflammation [14] and allergic reactions [15] to severe tissue necrosis [16], osteolysis [16, 17], and even pseudotumor formation [18].

Surface treatments currently employed attempt to minimize corrosion and wear of metallic alloys either by controlling the thickness and uniformity of the passive oxide layer (electropolishing and anodic oxidation) or by depositing solid, thin film coatings. For example, titanium nitride (TiN) and aluminum nitride (AlN) coatings have been shown to mitigate metal ion release and wear damage for titanium and cobalt chromium alloys [3, 19]. Despite the improved corrosion and wear behavior, these surface coatings have been observed to undergo failure under in vitro testing and in vivo conditions due to delamination and cracking [3,20]. Similarly, other surface treatments aimed at improving the corrosion and wear behavior fail once the integrity of the coating or oxide layer has been compromised. In certain situations, coating delamination can create wear particles, which can participate in the wear process (third body wear mechanism) and perform even more poorly than non-coated surfaces [20].

Recently, a new class of compounds called ionic liquids (ILs) is being investigated as corrosion inhibitors and lubricants for metals and their alloys. ILs are a class of chemical compounds that are essentially salts (composed of cationic and anionic moieties) existing in the liquid phase at temperatures below $100{ }^{\circ} \mathrm{C}$ [21]. Due to their chemical structure, ILs exhibit a unique set of properties under ambient environmental conditions including relatively low melting points over a wide range of temperatures, high thermal stability, high viscosity, negligible vapor pressure, and a wide electrochemical window meaning that ILs can undergo a relatively large amount of applied electrochemical potential before becoming oxidized or reduced [21]. Furthermore, ILs can be fine-tuned to possess specific properties through strategic design of their chemical structure and functional groups of the constituent moieties. Selected IL formulations have been found to act as corrosion inhibitors for aluminum, steel, and titanium surfaces [22-24]. Due to their net electrical charge and functional groups, ILs are capable of remaining attached to the surface. Furthermore, ILs have demonstrated excellent lubricant activity for articulating titanium-steel, steel-steel, and aluminum-steel surfaces [23, 25, 26]. In particular, it was shown that selected IL formulations reacted with steel surfaces under tribological testing, forming protective tribofilms that reduced friction during articulation [25].

As part of our current efforts to develop multi-functional ILs to be applied as coatings for metallic implant surfaces, we demonstrated how dicationic imidazolium-based ILs can be designed to exhibit antimicrobial activity while maintaining minimal toxicity against mammalian cells [27, 28]. Moreover, ILs with amino acid-based anionic moieties were shown to have relatively high affinity for commercially pure titanium surfaces, resulting in the formation of stable film coatings which served as both efficient corrosion inhibitors and lubricants [27, 29, 30]. Continuing this work, we sought to characterize the ability of three selected dicationic imidazolium-based ILs (Table 1) to improve the corrosion and wear performance of two common biomedical alloys. Due to their relatively high hydrophobicity, we hypothesized that the selected ILs would exhibit stable coatings and hence improve corrosion behavior in aqueous environments in addition to forming lubricating films that separate contacting surfaces and hence lower wear generation.

\section{Materials and Methods}

\subsection{Materials}

1,8-Bis(3-methylimidazolium-1-yl)octane di[bis(trifluoromethylsulfonyl)imide] (IL1), 1,10-bis(3-methylimidazolium-1-yl)decane di[bis(trifluoromethylsulfonyl)imide] (IL2), and 1,10-bis(3methylimidazolium-1-yl)decane diphenylalanine (IL3) were synthesized (Table 1) via metathesis reactions (IL1 and IL2) and the Fukumoto method (IL3) using protocols previously established in the literature $[28,31]$. ILs were characterized using ${ }^{1} \mathrm{H}$ and ${ }^{13} \mathrm{C}$ nuclear magnetic resonance (NMR) and mass spectroscopy with results in accordance with the literature [28, 32].

\subsection{Sample Preparation}

Disk-shaped specimens (11 mm in diameter) of cold-worked, grade 5 titanium-6aluminum-4vanadium (Ti6Al4V) and high nitrogen, low carbon, wrought cobalt-28chromium-6molybdenum (Co28Cr6Mo) manufactured per ASTM B348-13 and ASTM F1537-11, respectively, were used in this study. The 
Table 1 Chemical structure of the dicationic ionic liquids used in this study

Ionic liquid Cationic moiety

specimen cross-sectional areas were rough-polished sequentially using 240, 360, 600, 800, and 1200 grit $\mathrm{SiC}$ paper and then fine-polished using 1- $\mu \mathrm{m}$ polycrystalline diamond followed by $0.05-\mu \mathrm{m}$ nanometer alumina on a polisher mounted with an automated polishing head (NANO 1000T and FEMTO 1100, Pace Technologies). Specimens were then cleaned by ultrasonication while sequentially immersed for $15 \mathrm{~min}$ in acetone, deionized water, and ethanol. Specimens were then dried in an oven for $24 \mathrm{~h}$ at $60^{\circ} \mathrm{C}$. For electrochemical testing, alligator clips were used to establish an electrical connection with the specimen and then covered with electrical tape to isolate it. Two layers of an insulation coating (Miccrostop, Tolber Chemical Division) were then applied over the edges and lateral surface area of the specimens in order to only expose the polished surface area to the electrolyte. These specimens were then left to dry in an oven at $60{ }^{\circ} \mathrm{C}$ for $24 \mathrm{~h}$ to ensure complete drying of the insulation coating. As for those undergoing tribological testing, specimens were centered and mounted onto 40-mm stainless steel plates with the polished surface area upright using epoxy and left to cure for $24 \mathrm{~h}$ at room temperature (about $21^{\circ} \mathrm{C}$ ) to ensure adhesion to the mounting plates.

\subsection{IL Coating Procedure}

IL coating was applied via a drop casting technique where $5 \mu \mathrm{L}$ of IL ethanolic solutions $(40 \mathrm{mM})$ was pipetted onto the polished surface area and allowed to dry for $15 \mathrm{~min}$. This step was repeated ten times, with a total of $2 \mu \mathrm{mol}$ of IL being coated per specimen. All specimens (including control) were dried for $48 \mathrm{~h}$ at $60{ }^{\circ} \mathrm{C}$ before further testing (with the exception of IL1- and IL2-coated specimens due to observed mixing of these ILs with the insulation coating).

\subsection{Evaluation of IL Coating Stability}

Static immersion testing of IL-coated specimens $(\mathrm{n}=3)$ was performed to assess the relative coating stability by measuring the IL release concentration into $5 \mathrm{~mL}$ of $1 \times$ phosphate buffered saline (PBS) in capped glass vials (to minimize evaporation) at $37{ }^{\circ} \mathrm{C}$ over a period of 7 days. $10 \mu \mathrm{L}$ aliquots of the sample media was taken after $1 \mathrm{~h}, 1$, 3,5 , and 7 days of immersion and diluted with $10 \mu \mathrm{L}$ of PBS for IL3 and $10 \mu \mathrm{L}$ of ethanol for IL1 and IL2 (due to their low solubility in aqueous media). Peak absorbance readings of the diluted aliquots were taken using an ultraviolet-visible spectrophotometer (NanoDrop 2000c, Thermo Scientific) and correlated to IL concentration in PBS using previously established calibration curves (Figs. S1-S3). Readings taken after $1 \mathrm{~h}$ corresponded to the electrochemical testing time scale. Specimen images were taken using an optical microscope (VHX-2000 Digital Microscope, Keyence) before and after 7 days of immersion testing to qualitatively assess IL coating morphology.

\subsection{Electrochemical Testing}

Electrochemical testing of specimens $(n=6)$ was performed using a potentiostat (Interface 1000, Gamry Instruments) and a standard three-electrode electrochemical cell setup per ASTM F2129-15. The specimen being tested was the working electrode; the reference electrode was a saturated calomel electrode (SCE); the counter electrode was a graphite rod, and the electrolyte was PBS at $37^{\circ} \mathrm{C}$ under naturally aerated conditions. Prior to testing, parafilm was wrapped over the electrical tape to prevent condensation and possible fluid contact with the alligator clip. During testing, the open-circuit potential 
(OCP) was monitored first for $1 \mathrm{~h}$ to ensure electrochemical equilibrium was sufficiently achieved, and the final value was recorded as the OCP. Next, linear polarization resistance measurements were conducted within $\pm 10 \mathrm{mV}$ of OCP at a scan rate of $0.1667 \mathrm{mV} / \mathrm{s}$ based on ASTM G59-05. Afterward, anodic Tafel plots were obtained for the same specimen by polarizing the sample from OCP to $250 \mathrm{mV}$ above OCP at a scan rate of $1 \mathrm{mV} / \mathrm{s}$ in the anodic direction. The corrosion potential ( $\left.\mathrm{E}_{\mathrm{corr}}\right)$ measured from the Tafel plots was determined to be similar in value $( \pm 2 \mathrm{mV})$ to the OCP which ensured that no samples were significantly changed during polarization resistance measurements. The anodic Tafel constant $\left(\beta_{\mathrm{a}}\right)$ and corrosion current density $\left(i_{\text {corr }}\right)$ were then extrapolated from the linear region of the anodic Tafel plots (using $\beta_{\mathrm{a}}$ in place of the cathodic Tafel constant, $\beta_{c}$ ). Based on $i_{\text {corr }}$, the corrosion rate (CR) was calculated per ASTM G102-89. IL corrosion inhibition was quantified by calculating inhibition efficiency (IE) according to Eq. 1:

Inhibition Efficiency(IE)

$$
=\left[\left(i_{\text {corr,control }}-i_{\text {corr }, I L-c o a t e d}\right) /\left(i_{\text {corr,control }}\right)\right] \times 100 \% \text {. }
$$

\subsection{Tribological Testing}

A ball-on-disk tribological setup was employed under room temperature (about $21^{\circ} \mathrm{C}$ ) and laboratory air conditions using a hybrid rheometer (DHR-3, TA Instruments) per ASTM G99-05 and ASTM G133-05. Due to the poor wear resistance of Ti6Al4V, especially under dry testing conditions [33], Ti6Al4V balls were made to articulate against Ti6Al4V disk specimens while stainless steel balls slid against Co28Cr6Mo disk specimens. During testing $(\mathrm{n}=3)$, the metal ball slid in a circular, continuous sliding motion against the flat specimen surface at a speed of $5 \mathrm{~cm} /$ $\mathrm{s}$ under an applied axial load of 5 or $10 \mathrm{~N}$ for $1000 \mathrm{~s}(50 \mathrm{~m}$ sliding distance), which corresponded to maximum elastic contact stresses of about $463 \mathrm{MPa}$ and $584 \mathrm{MPa}$, respectively, while the coefficient of friction (COF) was recorded at a sampling frequency of $1 \mathrm{~Hz}$. Control specimens were lubricated with $50 \mu \mathrm{L}$ of PBS. Afterward, specimens were carefully removed and cleaned with acetone to remove residual IL coating and wear debris before further analysis. The total wear volume loss was quantified by averaging 6 individual wear track width measurements using optical microscopy based on Eqs. 2-4 provided in ASTM G99-05:

Disk volume loss $=2 \pi R\left[r^{2} \sin ^{-1}\left(\frac{d}{2 r}\right)-\left(\frac{d}{4}\right)\left(4 r^{2}-d^{2}\right)^{\frac{1}{2}}\right]$
Pin volume loss $=\left(\frac{\pi \mathrm{h}}{6}\right)\left(\frac{3 \mathrm{~d}^{2}}{4}+\mathrm{h}^{2}\right)$

$h=r-\left(r^{2}-\frac{d^{2}}{4}\right)^{\frac{1}{4}}$

The wear track radius $\mathrm{R}$ was fixed at $1.25 \mathrm{~mm}$; the diameter of the spherical pin or ball is $\mathrm{d}$; the wear track width measured from the wear scar on the disk (and assumed to be the same as that of the wear scar on the ball) is $\mathrm{r}$; and the maximum height or depth of the wear scar is $\mathrm{h}$.

One sample of each test condition that underwent tribological testing under $10 \mathrm{~N}$ was selected and wiped clean using ethanol in order to study the chemical composition with a PHI 5000 Versa Probe II X-ray Photoelectron Spectrometer with an $\mathrm{Al} \mathrm{K} \alpha(1486.7 \mathrm{eV}) \mathrm{X}$-ray source. The vacuum chamber was maintained at about $10^{-8}$ Torr throughout testing; the pass energy was fixed at 187.5/ $23.5 \mathrm{eV}$ with a step size of $0.8 / 0.2 \mathrm{eV}$ during the survey/ elemental scans. Based on the manufacturer's specifications, the detection accuracy was within $\pm 0.1 \mathrm{eV}$. Data analysis was performed using CasaXPS 2.3.17 software (RBD Instruments, Inc.). Per our previous study [30], energy calibration of XPS spectra was performed by setting the carbon $\mathrm{C} 1 \mathrm{~s}$ peak to $285.0 \mathrm{eV}$.

\subsection{Statistical Analysis}

One-way ANOVA followed by post hoc Tukey's test was employed to detect any significant differences between mean values of the measured parameters $(\alpha=0.05)$. Levene's test was used to detect any significant differences between the variances of the parameters being studied.

\section{Results}

\subsection{Coating Stability}

Coating morphology of IL-coated Ti6Al4V and Co28Cr6Mo (with applied red insulation coating) before and after immersion testing is shown in Fig. 1. All IL coatings exhibited heterogeneity; IL1 coating exhibited the most heterogeneity with significant clumping (Fig. 1b, i) followed by IL2 with smaller bead-shaped aggregates than IL1 (Fig. 1c, j) and then IL3 (Fig. 1d, k). After 7 days of immersion in PBS at $37{ }^{\circ} \mathrm{C}$, specimens previously coated with IL (Fig. 1e-g, 1-n) only had precipitates on their surface which crystallized after drying. However, a goldlike hue characteristic of IL3 was still present on the surfaces coated with IL3. The release profile of IL in PBS at 
Fig. 1 Images of non-coated control, IL1-, IL2-, and IL3coated Ti6Al4V (a-d) and Co28Cr6Mo (h-k) before and after (e-g, l-n) 7 days of static immersion in PBS. Note the significant aggregation of IL1, IL2, and IL3 (red, yellow, and blue arrows, respectively) and the opaque white substance (black arrows) on the surface that is precipitated salt from the immersion media (Color figure online)

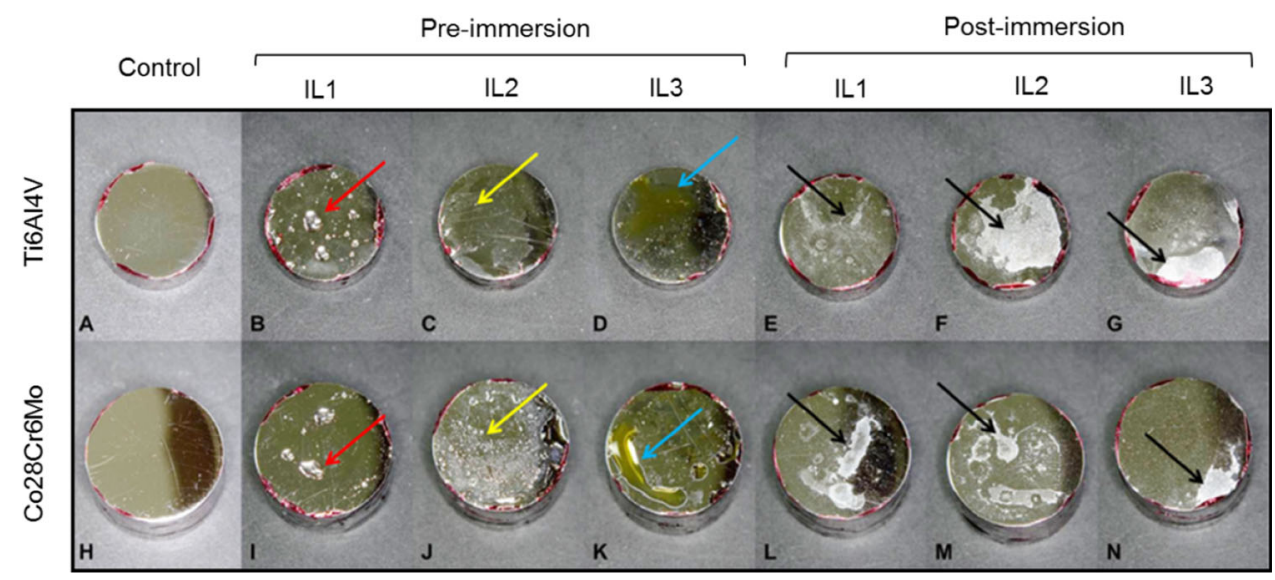

$37^{\circ} \mathrm{C}$ over a period of 7 days is shown in Fig. 2 (release concentration in Fig. S4). IL2-coated specimens initially had the lowest average amount of release (about $20 \%$ ) after $1 \mathrm{~h}$ on Ti6Al4V and Co28Cr6Mo, followed by IL1 (about 30-40 \%) and IL3 (about 70-80 \%). However, after $24 \mathrm{~h}$ of immersion and thereafter, about 100, 90-95, and 75-85\% of IL1, IL2, and IL3 coatings, respectively, had been released on both Ti6Al4V and Co28Cr6Mo.

\subsection{Corrosion Behavior}

All IL-coated Ti6Al4V displayed significantly lower $\mathrm{E}_{\text {corr }}$ values in comparison to control $(\mathrm{p}<0.05)$ while IL-coated Co28Cr6Mo did not (Fig. 3a). OCP ( $\left.\mathrm{E}_{\text {corr }}\right)$ values tended to increase with time as they became less negative (Figs. S5, S6). Based on the linear polarization curves (Figs. S7, S8), no significant differences in $\mathrm{R}_{\mathrm{p}}$ values measurements were observed for control and IL-coated Ti6Al4V (Fig. 3b). However, IL2 on average lowered the $R_{p}$ relative to noncoated control while IL3 increased it such that a significant difference was observed ( $\mathrm{p}<0.05$ ) between IL2 and IL3. As for IL1, $R_{p}$ values were similar to that of control Ti6Al4V. Like the $\mathrm{E}_{\text {corr }}$ values, no significant differences were observed between $R_{p}$ measurements for Co28Cr6Mo ( $p>0.05$ ). However, IL3 coating had the highest average

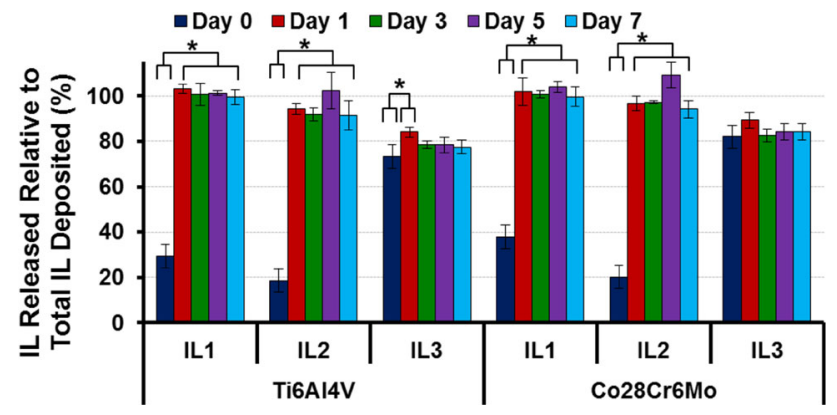

Fig. 2 Percentage of IL released from the specimen surface into PBS relative to total amount of IL initially coated on disk. "*” denotes a significance level of $\mathrm{p}<0.05$ (Color figure online)
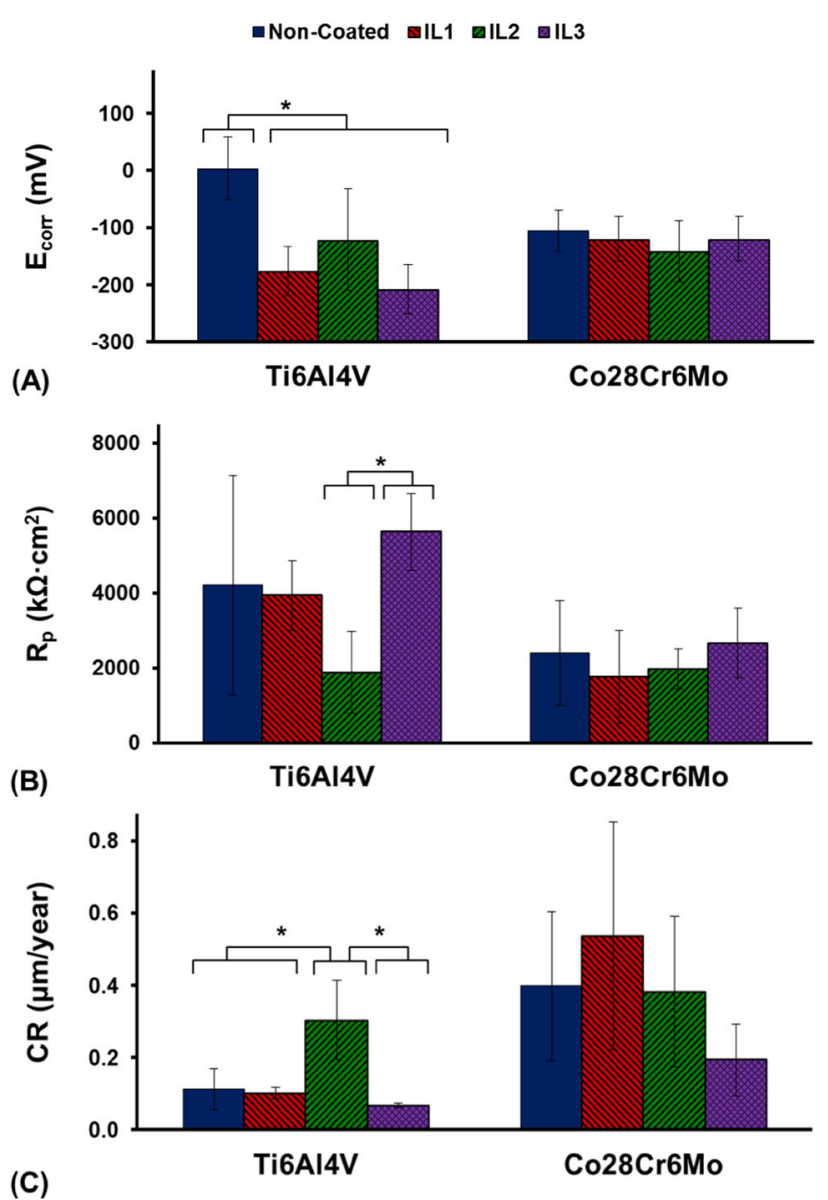

Fig. 3 a Corrosion potential $\left(E_{\text {corr }}\right)$, b polarization resistance $\left(R_{p}\right)$, and $\mathbf{c}$ corrosion rate (CR) of Ti6Al4V and Co28Cr6Mo. "*” denotes a significance level of $\mathrm{p}<0.05$ (Color figure online)

value on Co28Cr6Mo, followed by control, IL2, and IL1. As confirmed in other studies, the corrosion resistance of Ti6Al4V was on average higher than that of Co28Cr6Mo [34, 35]. Using anodic Tafel plots (Figs. S9, S10), IL2coated Ti6Al4V had significantly higher corrosion rates ( $p<0.05$ ) in comparison to control, IL1, and IL3 (Fig. 3c). 
On the other hand, no significant differences were observed between the control and IL-coated Co28Cr6Mo ( $\mathrm{p}>0.05)$.

Inhibition efficiency (IE) calculations showed that IL3 coating inhibited corrosion to the greatest extent for Ti6Al4V (Table 2). On the other hand, IL1 coating only slightly inhibited corrosion on Ti6Al4V while IL2 coating actually exhibited negative IE, meaning that it actually promoted corrosion of $\mathrm{Ti} 6 \mathrm{Al} 4 \mathrm{~V}$, and had a significantly lower $\beta_{\mathrm{a}}(\mathrm{p}<0.01)$. Although no significant differences were observed among IE for Co28Cr6Mo ( $p>0.05$ ), IL3 coating again exhibited the highest average IE and had a significantly higher $\beta_{\mathrm{a}}(\mathrm{p}<0.001)$ while IL2 coating was only slightly inhibitory. In contrast, IL1-coated Co28Cr6Mo presented moderate corrosion activator behavior.

\subsection{Tribological Testing}

Images of the wear scars generated after tribological testing are shown in Fig. 4. In general, Co28Cr6Mo specimens clearly exhibited thinner wear scars in comparison to corresponding Ti6Al4V specimens. Also, all samples previously coated with IL displayed much thinner wear scars in comparison to their respective controls lubricated with only PBS at both 5 and $10 \mathrm{~N}$, with the exception of two IL3coated Ti6Al4V (Fig. 4d, h).

For Ti6Al4V, COF values of control, PBS-lubricated specimens were maintained at a value of about 0.3 during testing at both 5 and $10 \mathrm{~N}$ (Fig. 5a, b). In contrast, IL1- and IL2-coated Ti6A14V initially exhibited similar COF values that drastically decreased and stabilized at a value of about 0.1 with the exception of a few short-burst increases or "spikes" in the COF. Although IL3-coated Ti6Al4V also approached this stable value, the time to reach it was considerably longer, especially when a $5 \mathrm{~N}$ load was applied. In contrast, all IL-coated Co28Cr6Mo exhibited lower COF (about 0.1) relative to PBS-lubricated ones at both 5 and $10 \mathrm{~N}$ (Fig. 5c, d).

Overall, COF values were significantly lower $(\mathrm{p}<0.05)$ for IL-coated samples in comparison to PBS-lubricated ones, with the exception of the IL3-coated Ti6Al4V specimens under an applied axial load of $10 \mathrm{~N}$ (Fig. 6). Correspondingly, total wear volume losses for IL-coated specimens were significantly reduced $(p<0.05)$ in comparison to control (Fig. 7) and were especially lower (an order of magnitude) for Co28Cr6Mo (Fig. 7b).

XPS results showed that the chemical environment of the constituent elements was similar for both the control and wear scar regions. For Ti6Al4V, the $\mathrm{Ti}_{2} \mathrm{p}_{3 / 2}$ peak was located at a binding energy (BE) of $458.6 \mathrm{eV}$ (Fig. 8a) while the $\mathrm{Ti} 2 \mathrm{p}_{1 / 2}$ peak was located at $464.3 \mathrm{eV}$, which is characteristic of titanium in its native oxide state $\left(\mathrm{Ti}^{4+}\right.$, $\mathrm{TiO}_{2}$ ) [36, 37]. Correspondingly, the BE of oxygen based on the O1s spectra (Fig. 8b) was located at $530.0 \mathrm{eV}$, which is typical for oxygen present in $\mathrm{TiO}_{2}$ [36]. A second, lower intensity peak for oxygen was located at $531.1 \mathrm{eV}$ and is attributed to hydroxyl groups typically found on the outermost layer of hydrated titanium surfaces. Other peak components located in the higher BE tail of the O1s spectra are associated with adventitious carbon species, which contaminate the surface upon exposure to air [36]. Aluminum in its oxide form $\left(\mathrm{Al}_{2} \mathrm{O}_{3}\right)$ comprised about $6 \%$ of the surface in accordance with its stoichiometric ratio in Ti6Al4V. Other trace elements detected were calcium, nitrogen, and silicon; phosphorus was also detected for Ti6Al4V exposed to PBS, suggesting the incorporation of calcium phosphate, $\mathrm{Ca}_{3}(\mathrm{PO})_{4}$, into the oxide layer as seen in previous studies [38, 39].

Like Ti6Al4V, the chemical composition of Co28Cr6Mo did not vary across all samples. On Co28Cr6Mo, only primary alloy constituent elementscobalt $(\mathrm{Co})$, chromium $(\mathrm{Cr})$, and molybdenum (Mo)-were detected along with oxygen and carbon (Fig. 9) at BEs established in the literature [4, 40, 41] along with no other trace elements. Based on the $\mathrm{Cr} 2 \mathrm{p}_{3 / 2}$ peak, $\mathrm{Cr}$ was found to be present in both its native oxide $\left(\mathrm{Cr}_{2} \mathrm{O}_{3}\right)$ and hydrated $\left(\mathrm{Cr}(\mathrm{OH})_{3}\right)$ forms (Fig. 9a) in addition to bulk $\mathrm{Cr}$ metal. In contrast, the Co2p spectra revealed Co present only in its metallic state (Fig. 9b). Low intensity yet broadened Mo3d $\mathrm{d}_{5 / 2}$ and $\mathrm{Mo}_{3 / 2}$ spectra indicated the presence of molybdenum oxide $\left(\mathrm{MoO}_{3}\right)$ and metallic Mo (Fig. 9c). The
Table 2 The anodic Tafel constant $\left(\beta_{\mathrm{a}}\right)$, corrosion current density $\left(\mathrm{i}_{\text {corr }}\right)$, and inhibition efficiency (IE) of Ti6Al4V and Co28Cr6Mo specimens immersed in PBS at $37^{\circ} \mathrm{C}$

\begin{tabular}{lllll}
\hline Material & IL coating & $\beta_{\mathrm{a}}(\mathrm{V} /$ decade $)$ & $\mathrm{i}_{\text {corr }}\left(\mathrm{nA} / \mathrm{cm}^{2}\right)$ & IE $(\%)$ \\
\hline Ti6A14V & Non-coated & $0.227 \pm 0.025$ & $13.08 \pm 6.50$ & - \\
& IL1 & $0.215 \pm 0.022$ & $11.80 \pm 1.85$ & $9.7 \pm 14.2$ \\
& IL2 & $0.139 \pm 0.040^{*}$ & $35.34 \pm 12.69$ & $-170.2 \pm 97.0$ \\
Co28Cr6Mo & IL3 & $0.229 \pm 0.010$ & $7.74 \pm 0.81$ & $40.8 \pm 6.2$ \\
& Non-coated & $0.160 \pm 0.027$ & $42.67 \pm 22.05$ & - \\
& IL1 & $0.146 \pm 0.023$ & $57.58 \pm 33.88$ & $-34.9 \pm 79.4$ \\
& IL2 & $0.156 \pm 0.007$ & $41.10 \pm 22.27$ & $3.7 \pm 52.2$ \\
& IL3 & $0.266 \pm 0.045^{*}$ & $20.76 \pm 10.68$ & $51.4 \pm 25.0$ \\
\hline
\end{tabular}

“*” denotes significantly different $(\mathrm{p}<0.01)$ than all other groups 
Fig. 4 Optical microscopy images of PBS-lubricated, IL1-, IL2-, and IL3-coated Ti6Al4V disk specimens tested at $5 \mathrm{~N}$ (ad) and $10 \mathrm{~N}(\mathbf{e}-\mathbf{h})$ and corresponding Co28Cr6Mo disk specimens $(\mathbf{i}-\mathbf{p})$

Fig. 5 Representative curves depicting coefficient of friction over sliding distance for contacting Ti6Al4V-Ti6Al4V surfaces under applied axial loads of $\mathbf{a} 5 \mathrm{~N}$ and $\mathbf{b} 10 \mathrm{~N}$ and contacting Co28Cr6Mostainless steel surfaces under applied loads of $\mathbf{c} 5 \mathrm{~N}$ and d $10 \mathrm{~N}$ (Color figure online)
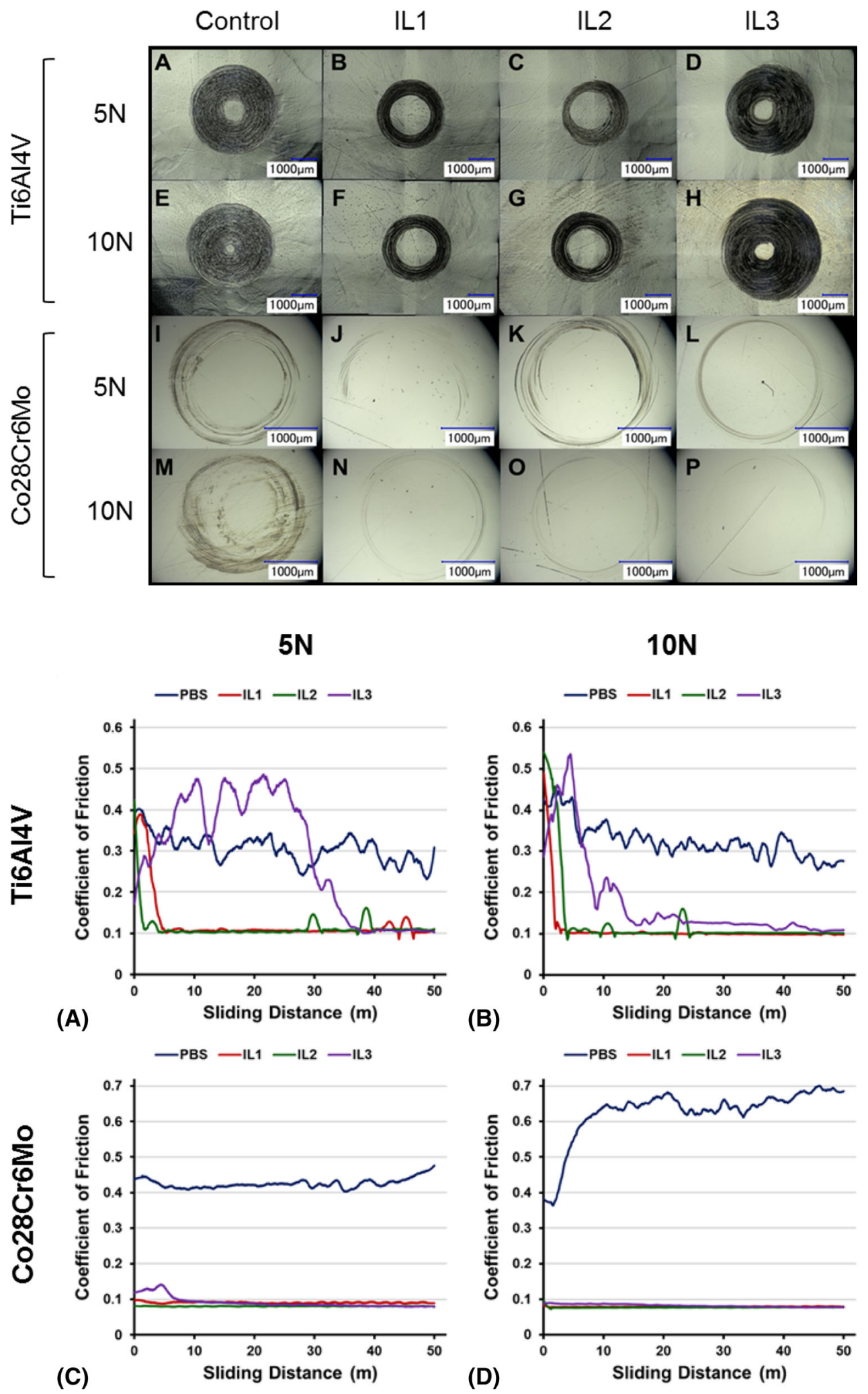

BEs of the O1s spectral components indicated the presence of metal oxide, hydroxide, and adventitious carbon contamination (Fig. 9d). Most of the carbon present was due to contamination although a small peak at the lower BE tail indicated the presence of metal carbides present in the bulk. 


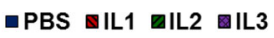

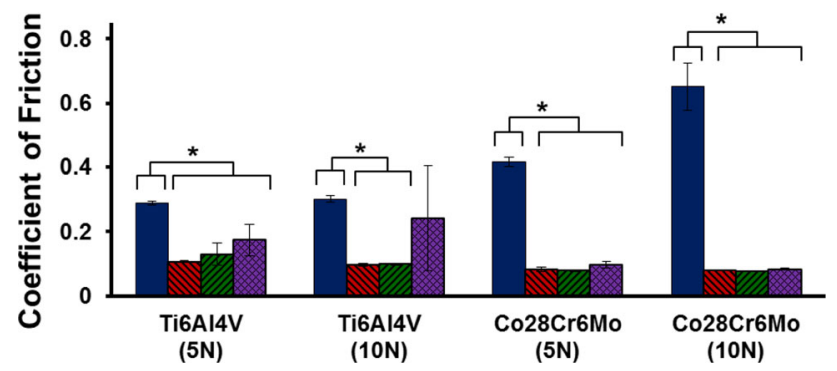

Fig. 6 Average coefficient of friction values for control (PBSlubricated) and IL-coated Ti6Al4V and Co28Cr6Mo samples under applied axial loads of 5 and $10 \mathrm{~N}$. "** denotes a significance level of $\mathrm{p}<0.05$ (Color figure online)

\section{Discussion}

The goal of this study was to investigate the corrosion behavior and wear performance of two common biomedical alloys-Ti6A14V and Co28Cr6Mo_-coated with three

-PBS IIL1 IL2 IL3

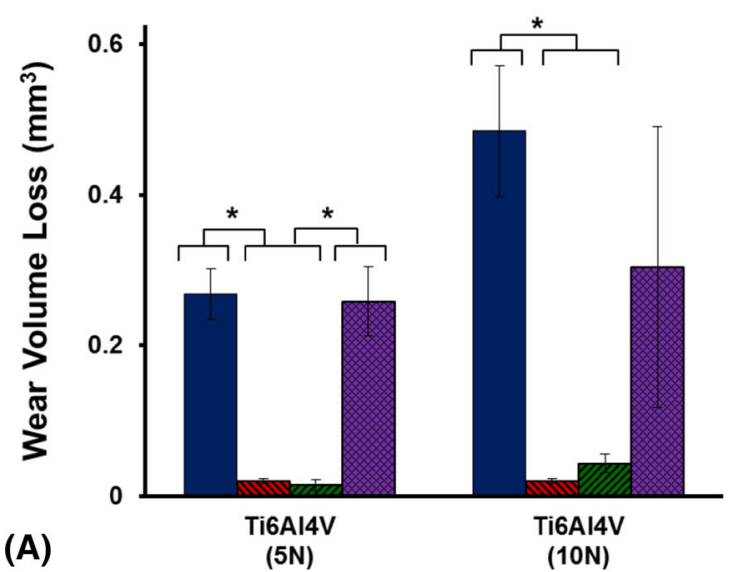

selected IL formulations. In previous studies, the selected ILs, dicationic imidazolium-based ILs with phenylalanine and bis(trifluoromethylsulfonyl)imide $\left(\mathrm{NTf}_{2}\right)$ as the anionic moieties, were shown to interact and form coatings on commercially pure titanium (cpTi) surfaces [27, 30]. Also, IL3 (phenylalanine) was previously shown to form stable coatings on cpTi when immersed in PBS and artificial saliva at room temperature that increased corrosion resistance and reduced wear generation $[27,29]$.

In general, IL release from Ti6Al4V and Co28Cr6Mo surfaces into PBS was found to stabilize after $24 \mathrm{~h}$ of immersion as no significant differences in amount released were observed after one day as shown in Fig. 2 ( $p>0.05$ ). Similarly, the release profile for each IL was found to not significantly differ between Ti6Al4V and Co28Cr6Mo $(\mathrm{p}>0.05)$. Although IL1 and IL2 coatings initially had lower release amounts after $1 \mathrm{~h}$, the coatings were nearly entirely dissolved into solution by $24 \mathrm{~h}$ and all time points thereafter. As corrosion testing was performed after

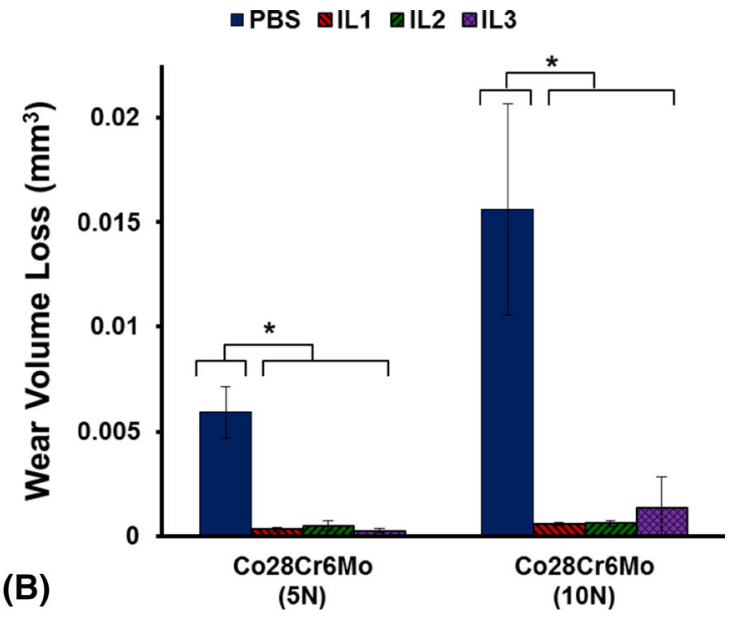

Fig. 7 Average total wear volume loss for control (PBS-lubricated) and IL-coated a Ti6A14V and b Co28Cr6Mo samples under applied axial loads of 5 and $10 \mathrm{~N}$. "*” denotes a significance level of $\mathrm{p}<0.05$ (Color figure online)
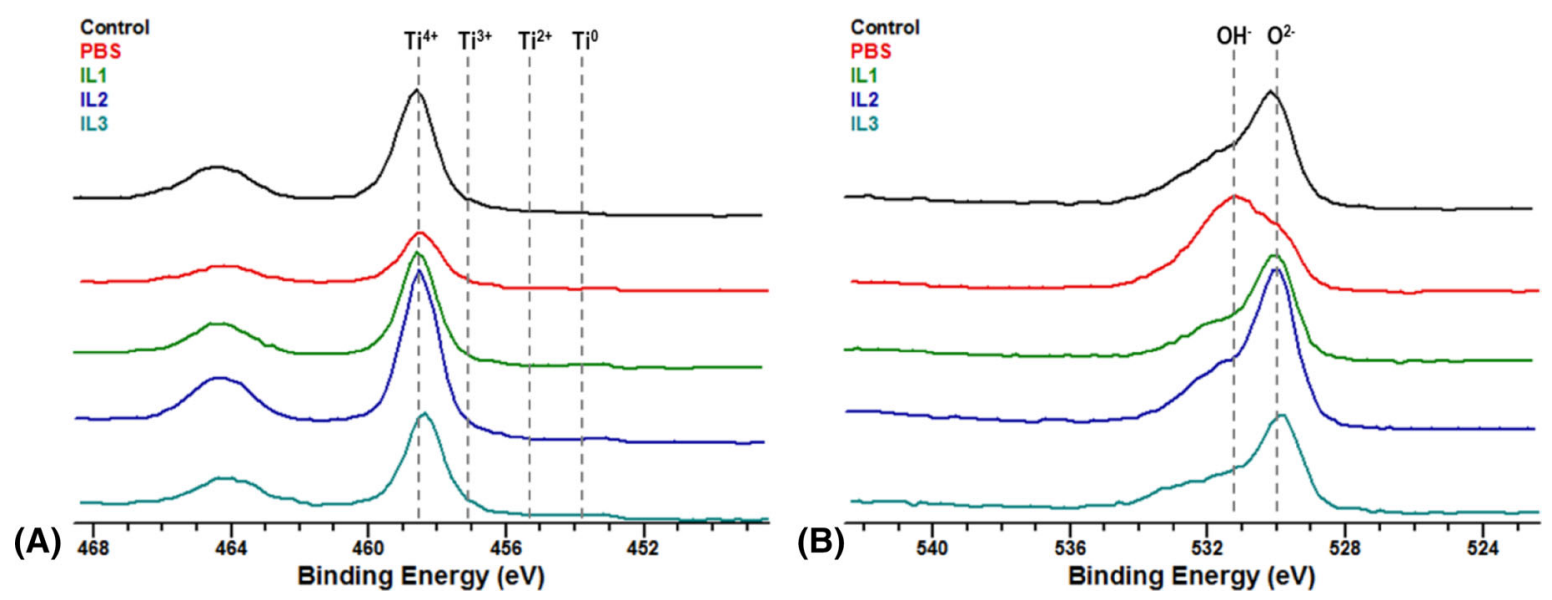

Fig. 8 a Ti2p and b O1s spectra of pristine surface and worn Ti6A14V specimens sliding against Ti6A14V when lubricated with PBS, IL1, IL2, and IL3 (Color figure online) 


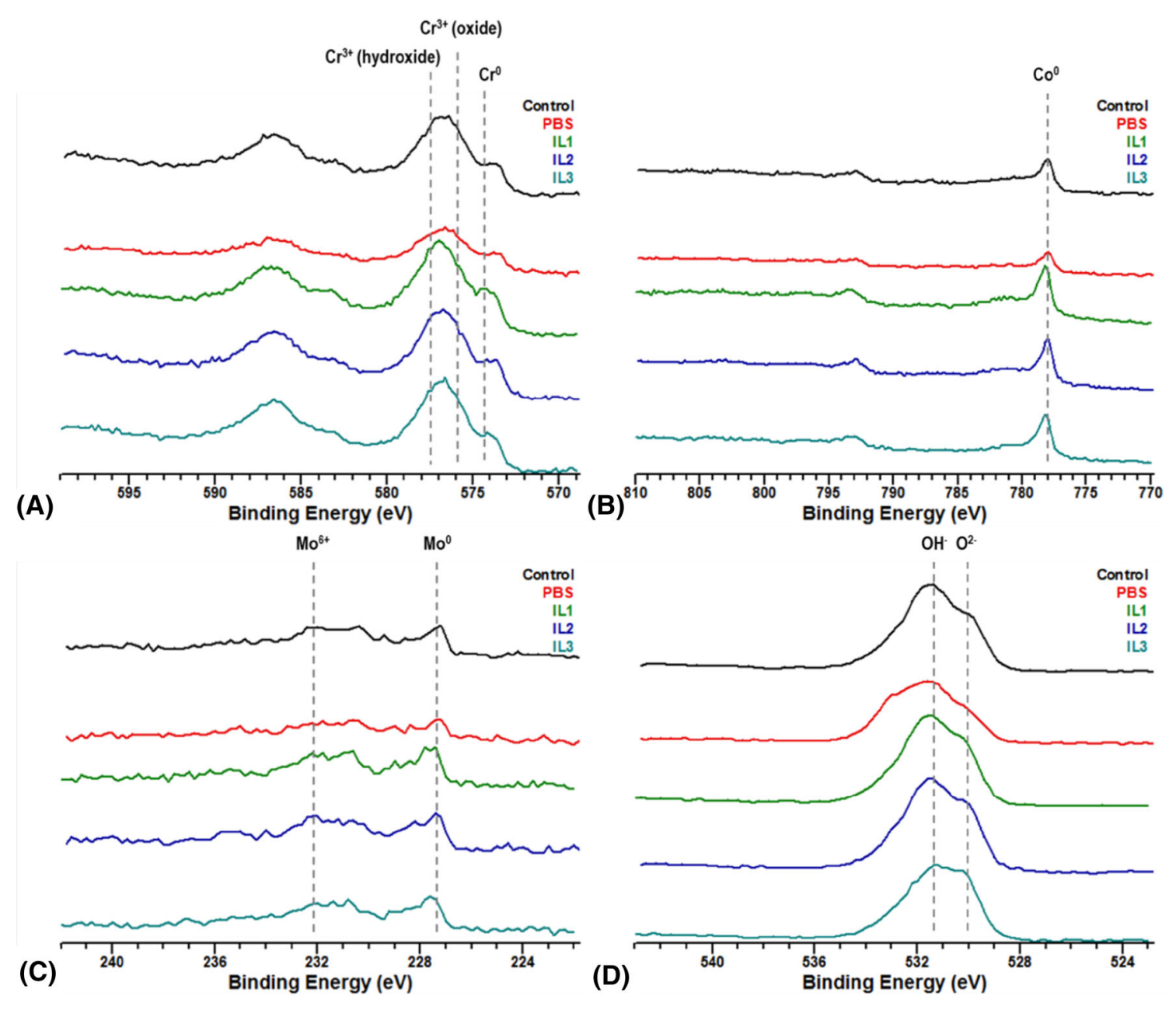

Fig. 9 a Cr2p, b Co2p, c Mo3d, and d O1s spectra of pristine and worn Co28Cr6Mo specimens sliding against stainless steel when lubricated with PBS, IL1, IL2, and IL3 (Color figure online)

specimens were immersed for $1 \mathrm{~h}$, any observed trends in corrosion behavior of IL1 and IL2 coatings would only be temporary since these coatings were shown to be unstable in PBS. In contrast, IL3 release into PBS (about $80 \%$ ) stabilized after the first hour of immersion, suggesting that a stable film immediately formed and that any improvement in corrosion behavior would continue to be observed beyond the first hour of immersion.

The trends observed in IL coating release profile appeared to correlate well with the level of heterogeneity observed in IL coating (Fig. 1). IL1 exhibited significant beading and clumping on both Ti6Al4V and Co28Cr6Mo (Fig. 1b, i), suggesting minimal interaction between this IL and the alloy surfaces which resulted in an unstable IL film. Similarly, clumping of IL also appeared on IL2-coated specimens (Fig. 1c, j). Similarly, the release profile of IL2 coating demonstrated that it was also unstable on Ti6Al4V and Co28Cr6Mo surfaces despite having aggregates smaller than IL1 (Fig. 1c, j). In contrast, a brownish-yellow discoloration characteristic of IL3 present across the entire specimen surface area demonstrated strong interaction with Ti6Al4V and Co28Cr6Mo (Fig. 1d, k) and hence stable IL film formation. Although some amount of IL clumping is observed, this is due to coating with excess IL which saturated the surface, leaving some IL free to aggregate on the surface. After immersion testing, IL1- (Fig. 1e, 1) and IL2coated (Fig. 1f, m) samples appeared to have lost most of their coating, and crystallized salts are assumed to be present on its surface after evaporation of the immersion media. On the other hand, IL3-coated specimens (Fig. 1g, n) only exhibited salt precipitates near its edges with the remaining surface appearing to show a brownish-yellow discoloration typical of IL3.

$E_{\text {corr }}$ measurements (Fig. 3a) allowed for probing of the thermodynamic stability of IL coatings on Ti6Al4V and Co28Cr6Mo. Unlike IL3-coated cpTi [29], IL-coated Ti6Al4V exhibited $\mathrm{E}_{\text {corr }}$ values significantly lower than that of control Ti6Al4V. As seen in other studies analyzing films formed due to protein adsorption on cpTi and Co28Cr6Mo, a reduction in $\mathrm{E}_{\text {corr }}$ can be attributed to 
incomplete coverage of the adsorbate on the surface $[42,43]$. Similarly, the lower $\mathrm{E}_{\text {corr }}$ observed for Ti6Al4V suggests that IL3 did not form a complete, compact film like IL3-coated cpTi in PBS [29]. This result can be attributed to structural and compositional differences between the oxide layers of cpTi and Ti6Al4V, with the latter presenting $\mathrm{Al}$ on its surface. Such differences could result in greater defects and discontinuities in the oxide layer. As a result, IL might have not adhered to the oxide layer in these regions, resulting in a porous IL film. In previous studies involving steel surfaces, monocationic imidazolium-based ILs were found to behave as mixedtype corrosion inhibitors (inhibiting both anodic and cathodic reactions) but primarily acted as cathodic inhibitors [44-46] and thus lowered $\mathrm{E}_{\text {corr }}$ relative to control samples [47]. However, this effect would be temporary for IL1 and IL2 which eventually were entirely released. As for $\mathrm{Co} 28 \mathrm{Cr} 6 \mathrm{Mo}$, the lack of significantly different $\mathrm{E}_{\text {corr }}$ values indicated that any observed corrosion inhibition would primarily be mixed type.

IL1 and IL2 exhibited a lower average $R_{p}$ in comparison to control while IL3 had a higher $R_{p}$ on both Ti6Al4V and Co28Cr6Mo (Fig. 3b). However, these differences were much more pronounced for IL coatings on Ti6Al4V. Interestingly, the same trends that were observed for decreasing $R_{p}$ values correlated with the increasing corrosion rates (independently measured) on Ti6Al4V and Co28Cr6Mo, which is expected as $R_{p}$ and corrosion rates are inversely proportional according to the Stern-Geary equation. That is, for Ti6Al4V, IL3 had the lowest corrosion rate, followed by IL1/control and then IL2. Similarly, IL3 exhibited the lowest corrosion rate followed by IL2/control, and finally IL1 on Co28Cr6Mo. Moreover, IL2-coated Ti6Al4V exhibited a significantly higher $(3 \times)$ corrosion rate $(\mathrm{p}<0.05)$ in comparison to other Ti6Al4V specimens, including IL1 (Fig. 3c). This result was interesting as the only difference between IL1 and IL2 is the number of carbon atoms in the alkyl spacer group ( 8 and 10 , respectively). An increase in chain length has been shown to increase hydrophobic interactions between the alkyl chains of IL molecules [48]. Thus, a greater amount of the more hydrophobic IL2 was retained on the surface in PBS in comparison to IL1 after $1 \mathrm{~h}$ of immersion. However, this weak adsorption of IL2 on Ti6Al4V is hypothesized to have created local-action corrosion cells as regions covered by IL served as anodes, undergoing metal ion dissolution, while the uncovered portions served as cathodes, compensating for increased metal ion release.

Despite the anionic moiety of IL3 (phenylalanine) having relatively lower hydrophobicity in comparison to that of IL1 and IL2 $\left(\mathrm{NTf}_{2}\right)$, IL3 on average decreased corrosion rates for both Ti6Al4V and Co28Cr6Mo. In our recent study, it was shown that hydrogen bonds formed between the anionic moieties of IL1, IL2, and IL3 and the hydroxyl groups present on titanium oxide [30] (which are also present on Co28Cr6Mo [49]). However, the interaction with the amine and carboxyl groups of IL3 was much stronger than the anionic moiety of IL1 [30]. Furthermore, recent studies have shown that imidazolium-based ILs which exhibit more hydrophilic character such as IL3 interact with hydroxyl groups functionalized on the surface of activated carbon $[50,51]$. In contrast, it was found that the adsorption of more hydrophobic ILs like IL1 and IL2 is highly dependent on van der Waals interaction and is lowered in the presence of functional groups like surface hydroxyl groups [50]. Therefore, we hypothesized that hydrogen bonds promoted film formation of IL3 on Ti6Al4V and Co28Cr6Mo but was hindered for IL1 and IL2. Additionally, IL1 and IL3 were observed to significantly reduce the variance in corrosion rate in comparison to control and IL2-coated Ti6Al4V $(\mathrm{p}<0.05)$. Predictable corrosion rates are valuable when corrosion of metals like magnesium alloy is desirable for biodegradable applications [52, 53].

Another often overlooked electrochemical parameter is the anodic Tafel constant, $\beta_{\mathrm{a}}$, (Table 2) which is used to derive $i_{\text {corr }}$. As a property of electrochemical reaction kinetics occurring on a metal surface [54], it is thus influenced by the surface conditions and can be used as a way to assess variability among the surface finishes of samples for given testing conditions. In this study, $\beta_{\mathrm{a}}$ demonstrated that IL2-coated Ti6Al4V and IL3-coated Co28Cr6Mo were electrochemically distinct from other Ti6Al4V and Co28Cr6Mo specimens $(\mathrm{p}<0.01)$, respectively, which corroborates the electrochemical results previously discussed.

Corrosion behavior of IL-coated specimens was further quantified in terms of inhibition efficiency (IE). IE values for IL3-coated Ti6Al4V were similar in value (40.8\%) to those observed for cpTi (about $35 \%$ ) under identical corrosion testing conditions [29], while IL3-coated Co28Cr6Mo actually exhibited a greater average IE value (51.4\%). According to Tanaka et al., Co28Cr6Mo contains higher concentrations of active surface hydroxyl groups than cpTi [49] and hence is expected to have a greater IE in comparison to Ti6Al4V. In contrast, the IE values of IL1 and IL2 coatings on Ti6Al4V and Co28Cr6Mo were near zero or even negative, confirming their poor performance as corrosion inhibitors for these surfaces despite the good protection afforded by their anionic moiety $\left(\mathrm{NTf}_{2}\right)$ on magnesium and carbon steel surfaces [22, 52].

Although IL1 and IL2 did not form stable coatings for the conditions tested in this study, it is possible that this may be also due to testing at $37^{\circ} \mathrm{C}$ instead of at room temperature and using a relatively large fluid volume ( $5 \mathrm{~mL}$ ), resulting in IL1 and IL2 coatings being completely 
solubilized in solution, as opposed to that $(1 \mathrm{~mL})$ used in our previous study [27]. Furthermore, as previously noted, IL1 and IL2 had to be coated at room temperature due to observed mixing with the insulation coating at $60{ }^{\circ} \mathrm{C}$. It is possible that IL1 and IL2 are still able to penetrate and mix with this insulation coating, allowing for an electrical path between the unpolished areas of specimens and electrolyte, which could result in the lower corrosion resistances observed in this study.

Currently, there are no commercial, biocompatible lubricants. Thus, IL-coated specimens undergoing tribological testing were only compared against those lubricated with PBS. Overall, IL-coated specimens clearly showed an improvement in wear performance as the wear scar sizes in general were significantly smaller in comparison to control samples that were only lubricated with PBS (Fig. 4) despite undergoing extreme contact pressures (about $100 \mathrm{MPa}$ ) which were at least an order of magnitude greater than those experienced at the hip and knee joints in vivo [55, 56]. Both IL1- and IL2-coated contacting Ti6Al4VTi6Al4V surfaces exhibited an immediate stable decrease in the COF shortly after tribological testing began that was maintained throughout testing, with the exception of a few spiking increases under 5 and $10 \mathrm{~N}$ axial applied loads (Fig. 5a, b). As demonstrated in previous studies, the mechanism of IL lubricant activity is explained to be the result of the formation of an anti-wear film where anions and cations are adsorbed onto metallic surfaces in successive layers, resulting in boundary lubrication conditions $[24,57]$. Furthermore, the presence of longer hydrophobic alkyl chains more effectively prevents direct contact between surface asperities, resulting in reduced wear $[23,25]$. In contrast, IL3-coated Ti6Al4V specimens exhibited COF values that at times were even higher than that of the PBS-lubricated samples. However, once the two contacting surfaces became accustomed to sliding against each other (running-in period), IL3-coated Ti6Al4V exhibited COF values similar to those observed for IL1 and IL2. In comparison to IL1 and IL2, IL3 is relatively more viscous when handled and applied as a coating on specimen surfaces, which may have rendered it slower in terms of reducing the COF. However, for contacting Co28Cr6Mo-stainless steel, all ILs were excellent lubricants, resulting in sustained and significantly lower COF, even at $10 \mathrm{~N}$ of applied load, without any spiking increases as observed for Ti6Al4V. On the other hand, the COF of PBS-lubricated specimens increased when the axial load was increased from 5 to $10 \mathrm{~N}$. On average, IL-coated specimens significantly reduced the COF relative to PBSlubricated specimens (Fig. 6) and subsequently had lower wear volume losses (Fig. 7), with the exception of IL3coated Ti6Al4V under $10 \mathrm{~N}$ of applied load. This may have been due to local depletion of IL3 which can be attributed to the heterogeneity of the IL coating (Fig. 1). Despite coating heterogeneity, IL1- and IL2-coated specimens on average still had lower COF values and subsequently lower wear volume losses. Thus, it can be concluded that IL1 and IL2 were more efficient in protecting articulating Ti6Al4V and Co28Cr6Mo surfaces.

XPS is a technique that provides information regarding the identity and environment of the chemical constituents within the first few nanometers of a given surface and thus is a powerful technique for probing surface changes due to wear. In general, the chemical composition of the pristine control and wear scar regions on both Ti6Al4V and Co28Cr6Mo were the same. In particular, titanium was found to be present in its native oxide form $\left(\mathrm{TiO}_{2}\right)$ and in its hydrated form $\left(\mathrm{Ti}(\mathrm{OH})_{4}\right)$ on $\mathrm{Ti} 6 \mathrm{Al} 4 \mathrm{~V}$ along with aluminum present as an oxide $\left(\mathrm{Al}_{2} \mathrm{O}_{3}\right)$, which is in accordance with other studies [36, 37]. Moreover, the O1s spectra further confirmed the presence of titanium oxide and hydroxide as both peak components were detected. On the other hand, vanadium oxide (primarily $\mathrm{V}_{2} \mathrm{O}_{5}$ ) was not detected because it is preferentially located near the metaloxide interface and thus could only be detected after sputtering the surface to remove superficial layers and oxide [58]. Interestingly, for PBS-lubricated Ti6Al4V, the Ti2p peak was lower in intensity relative to the pristine control surface and wear scar regions of IL-coated specimens (Fig. 8a). Correspondingly, the O1s peak components associated with $\mathrm{TiO}_{2}$ and $\mathrm{Ti}\left(\mathrm{OH}_{4}\right)$ were less intense than those associated with carbon contamination, resulting in an apparent shift of the overall O1s spectral peak to higher BE (Fig. 8b). Another interesting feature observed is the appearance of a lower BE tail end in the Ti2p spectra, corresponding to lower titanium oxidation states $\left(\mathrm{Ti}^{3+}\right.$, $\mathrm{Ti}^{2+}$, and $\mathrm{Ti}^{0}$ ), that was most pronounced for the IL3coated Ti6Al4V. As this specimen had undergone more wear, it may have had a thinner oxide layer relative to IL1and IL2-coated Ti6Al4V. However, the relatively high intensity of the Ti2p spectra for control and wear scar regions of all IL-coated specimens demonstrate that an oxide layer similar in thickness to control was able to regrow after tribological testing. Overall, these results highlight the benefit of using ILs to protect Ti6Al4VTi6Al4V contacting surfaces such as between the interfaces of modular implant components where severe corrosion and wear damage have been observed to occur $[59,60]$.

For Co28Cr6Mo specimens (Fig. 9), chromium and molybdenum were enriched in the outermost surface layer, primarily as chromium oxide $\left(\mathrm{Cr}_{2} \mathrm{O}_{3}\right)$ and molybdenum oxide $\left(\mathrm{MoO}_{3}\right)$, respectively, which is in agreement with previous works [4, 40, 41]. However, the oxide layer was thinner in comparison to that of Ti6Al4V as both chromium and molybdenum were also detected in their metallic 
states. In contrast to previous studies, cobalt was only detected in its metallic state and not as an oxide $(\mathrm{CoO})$ [41]. Due to its relatively high solubility in comparison to other oxides [4], cobalt oxide was probably removed from the surface during cleaning prior to tribological testing. Although this alloy composition is used primarily today due to its wear resistance, it can still undergo surface damage due to the synergistic effects of corrosion and wear (fretting corrosion and tribocorrosion) experienced in vivo $[7,8]$. Thus, by employing ILs as lubricants, wear-assisted corrosion and damage to the native oxide layer may be mitigated.

The absence of elements like fluorine in IL1 and IL2 within the wear scar regions analyzed in a previous study for steel surfaces suggests that the chemical integrity of IL was maintained for the tribological testing conditions employed in this study [25]. The lack of IL decomposition and reactivity with Ti6Al4V and Co28Cr6Mo under loading conditions is not only beneficial for sustained lubrication but also is advantageous from a biocompatibility perspective. Although these ILs were shown to exhibit minimal cytotoxicity suggesting their safe use in vivo, the toxicity of their decomposition products may be drastically different and would therefore warrant further biocompatibility testing.

Although ILs exhibited excellent lubrication properties for the tribological testing conditions applied in this study, future testing needs to be performed to overcome some of the limitations of the present work. First, although ILs were shown to improve wear performance under dry testing conditions, testing needs to be performed under wet testing conditions for longer sliding distances evaluated in previous studies to better simulate the moist, fluid environment surrounding implant surfaces $[23,25]$. That is, a wet environment can affect both the IL adsorption and lubricating activities. Furthermore, in vivo conditions such as $37{ }^{\circ} \mathrm{C}$ and the presence of proteins and other chemical species have not been investigated in this study and can certainly influence how IL lubricates metallic surfaces. Finally, although electrochemical and tribological performance was characterized separately in this study for ease of characterization, corrosion and wear processes occur synergistically in vivo, leading to more severe damage to metallic surfaces.

\section{Conclusion}

In summary, three selected dicationic imidazolium-based ILs were characterized based on their ability to form stable coatings, decrease corrosion susceptibility, and improve the wear performance of Ti6Al4V and Co28Cr6Mo. IL3 (with phenylalanine as the anion) favorably interacted with the alloys' surfaces and performed well as a corrosion inhibitor but less optimal as a lubricant while the reverse trend was observed for IL1 and IL2 (with $\mathrm{NTf}_{2}$ ). Despite the ability of ILs to form films with metal oxides, film formation does not guarantee corrosion inhibition if it is not stable. That is, IL chemical structure must be considered and fine-tuned relative to the coating substrate in order to improve corrosion and wear performance. Specifically, it is necessary to consider the functional groups of the IL constituent moieties and that of the substrate with which it will interact. Furthermore, this study demonstrates that the spacer groups in ILs can be critical in determining the degree of IL adsorption with increasing alkyl chain length resulting in higher IL hydrophobicity and hence influence its ability to inhibit corrosion.

Acknowledgments The authors acknowledge the University of Texas at Dallas (UTD) for providing financial support for this study (startup funds DCR), the Biomaterials for Osseointegration and Novel Engineering (BONE) Lab for providing the facilities for this research, a fellowship from Coordination for Improvement of Higher Education Personnel (CAPES) (IMG), Dr. Mathew T. Mathew for providing the Co28Cr6Mo specimens used in this study, and Catherine Davis for performing the tribological testing.

\section{Compliance with Ethical Standards}

Conflict of Interest On behalf of all authors, the corresponding author states that there is no conflict of interest.

\section{References}

1. Manivasagam G, Dhinasekaran D, Rajamanickam A (2010) Biomedical implants: corrosion and its prevention-a review. Recent Pat Corros Sci 2(1):40-54. doi:10.2174/187761080100 2010040

2. Fontana MG (1970) The 1970 Campbell Memorial Lecture, The American Society for metals perspectives on corrosion of materials. Metall Trans 1(12):3251-3266. doi:10.1007/BF03037851

3. Lausmaa J (2001) Mechanical, thermal, chemical and electrochemical surface treatment of titanium. In: Brunette DM, Tengvall $\mathrm{P}$, Textor $\mathrm{M}$, Thomsen $\mathrm{P}$ (eds) Titanium in medicine, 1st edn. Springer, Berlin, pp 231-266. doi:10.1007/978-3-642-56486-4

4. Milošev I, Strehblow H-H (2003) The composition of the surface passive film formed on CoCrMo alloy in simulated physiological solution. Electrochim Acta 48(19):2767-2774. doi:10.1016/ S0013-4686(03)00396-7

5. Bhola R, Bhola SM, Mishra B, Olson DL (2009) Electrochemical behavior of titanium and its alloys as dental implants in normal saline. Res Lett Phys Chem. 2009:1-4. doi:10.1155/2009/574359

6. Rodrigues DC, Valderrama P, Wilson TG Jr et al (2013) Titanium corrosion mechanisms in the oral environment: a retrieval study. Materials (Basel). 6(11):5258-5274. doi:10.3390/ma6115258

7. Yan Y, Neville A, Dowson D (2007) Biotribocorrosion of CoCrMo orthopaedic implant materials-assessing the formation and effect of the biofilm. Tribol Int 40(10-12):1492-1499. doi:10.1016/j.triboint.2007.02.019 
8. Swaminathan V, Gilbert JL (2012) Fretting corrosion of CoCrMo and Ti6Al4V interfaces. Biomaterials 33(22):5487-5503. doi:10. 1016/j.biomaterials.2012.04.015

9. Brown SA, Hughes PJ, Merritt K (1988) In vitro studies of fretting corrosion of orthopaedic materials. J Orthop Res 6(2):572-579. doi:10.1002/jor.1100060415

10. Gilbert JL, Sivan S, Liu Y, Kocagöz SB, Arnholt CM, Kurtz SM (2015) Direct in vivo inflammatory cell-induced corrosion of CoCrMo alloy orthopedic implant surfaces. J Biomed Mater Res Part A 103(1):211-223. doi:10.1002/jbm.a.35165

11. Brown SA, Flemming CAC, Kawalec JS et al (1995) Fretting corrosion accelerates crevice corrosion of modular hip tapers. J Appl Biomater 6(1):19-26. doi:10.1002/jab.770060104

12. Jacobs JJ, Skipor AK, Patterson LM et al (1998) Metal release in patients who have had a primary total hip arthroplasty. A prospective, controlled, longitudinal study. J Bone Jt Surg Am 80(10): 1447-1458

13. Willis-Owen CA, Keene GC, Oakeshott RD (2011) Early metallosis-related failure after total knee replacement: a report of 15 cases. J Bone Jt Surg 93(2):205-209. doi:10.1302/0301-620X. 93B2. 25150

14. Landgraeber S, Jäger M, Jacobs JJ, Hallab NJ (2014) The pathology of orthopedic implant failure is mediated by innate immune system cytokines. Mediat Inflamm 2014:1-9. doi:10. $1155 / 2014 / 185150$

15. Zeng Y, Feng W (2013) Metal allergy in patients with total hip replacement: a review. J Int Med Res 41(2):247-252. doi:10. 1177/0300060513476583

16. Willert HG, Semlitsch M (1977) Reactions of the articular capsule to wear products of artificial joint prostheses. J Biomed Mater Res 11(2):157-164. doi:10.1002/jbm.820110202

17. Magone K, Luckenbill D, Goswami T (2015) Metal ions as inflammatory initiators of osteolysis. Arch Orthop Trauma Surg 135(5):683-695. doi:10.1007/s00402-015-2196-8

18. Burbano M, Russell R, Huo M, Welch R, Roy D, Rodrigues DC (2014) Surface characterization of retrieved metal-on-metal total hip implants from patients with adverse reaction to metal debris. Materials (Basel). 7(3):1866-1879. doi:10.3390/ma7031866

19. Goldberg JR, Gilbert JL (2004) The electrochemical and mechanical behavior of passivated and TiN/AlN-coated CoCrMo and Ti6Al4V alloys. Biomaterials 25(5):851-864. doi:10.1016/ S0142-9612(03)00606-9

20. Van Hove RP, Sierevelt IN, Van Royen BJ, Nolte PA (2015) Titanium-nitride coating of orthopaedic implants: a review of the literature. Biomed Res Int. doi:10.1155/2015/485975

21. Johnson KE (2007) What's an ionic liquid? Electrochem Soc Interface 16(1):38-41

22. Diamanti M, Velardi U, Brenna A, Mele A, Pedeferri M, Ormellese M (2016) Compatibility of imidazolium-based ionic liquids for $\mathrm{CO}_{2}$ capture with steel alloys: a corrosion perspective. Electrochim Acta 192:414-421. doi:10.1016/j.electacta.2016.02. 003

23. Jiménez AE, Bermúdez MD (2009) Ionic liquids as lubricants of titanium-steel contact. Tribol Lett 33(2):111-126. doi:10.1007/ s11249-008-9396-0

24. Somers A, Howlett P, MacFarlane D, Forsyth M (2013) A review of ionic liquid lubricants. Lubricants. 1(1):3-21. doi:10.3390/ lubricants 1010003

25. Pagano F, Gabler C, Zare P et al (2012) Dicationic ionic liquids as lubricants. Proc Inst Mech Eng Part J 226(11):952-964. doi:10. 1177/1350650112458873

26. Qu J, Blau PJ, Dai S, Luo H, Meyer HM, Truhan JJ (2009) Tribological characteristics of aluminum alloys sliding against steel lubricated by ammonium and imidazolium ionic liquids. Wear 267(5-8):1226-1231. doi:10.1016/j.wear.2008.12.038
27. Gindri IM, Palmer KL, Siddiqui DA et al (2016) Evaluation of mammalian and bacterial cell activity on titanium surface coated with dicationic imidazolium-based ionic liquids. RSC Adv. 6(43):36475-36483. doi:10.1039/C6RA01003B

28. Gindri IM, Siddiqui DA, Bhardwaj P et al (2014) Dicationic imidazolium-based ionic liquids: a new strategy for non-toxic and antimicrobial materials. RSC Adv. 4(107):62594-62602. doi:10. 1039/C4RA09906K

29. Gindri IM, Siddiqui DA, Frizzo CP, Martins MAP, Rodrigues DC (2016) Improvement of tribological and anti-corrosive performance of titanium surfaces coated with dicationic imidazoliumbased ionic liquids. RSC Adv. 6(82):78795-78802. doi:10.1039/ C6RA13961B

30. Gindri IM, Siddiqui DA, Frizzo CP, Martins MAP, Rodrigues DC (2015) Ionic liquid coatings for titanium surfaces: effect of IL structure on coating profile. ACS Appl Mater Interface 7(49):27421-27431. doi:10.1021/acsami.5b09309

31. Shirota H, Mandai T, Fukazawa H, Kato T (2011) Comparison between dicationic and monocationic ionic liquids: liquid density, thermal properties, surface tension, and shear viscosity. J Chem Eng Data 56(5):2453-2459. doi:10.1021/je2000183

32. Gindri IM, Frizzo CP, Bender CR et al (2014) Preparation of $\mathrm{TiO}_{2}$ nanoparticles coated with ionic liquids: a supramolecular approach. ACS Appl Mater Interface 6(14):11536-11543. doi:10. 1021/am5022107

33. Chauhan SR, Dass K (2013) Dry sliding wear behaviour of titanium (Grade 5) alloy by using response surface methodology. Adv Tribol 2013:1-9. doi:10.1155/2013/272106

34. Gurappa I (2002) Characterization of different materials for corrosion resistance under simulated body fluid conditions. Mater Charact 49(1):73-79. doi:10.1016/S1044-5803(02)00320-0

35. Textor M, Sittig C, Frauchiger V, Tosatti S, Brunette DM (2001) Properties and biological significance of natural oxide films on titanium and its alloys. In: Brunette DM, Tengvall P, Textor M, Thomsen $\mathrm{P}$ (eds) Titanium in medicine. Springer, Berlin, pp 171-230. doi:10.1007/978-3-642-56486-4_7

36. Biesinger MC, Lau LWM, Gerson AR, Smart RSC (2010) Resolving surface chemical states in XPS analysis of first row transition metals, oxides and hydroxides: $\mathrm{Sc}, \mathrm{Ti}, \mathrm{V}, \mathrm{Cu}$ and $\mathrm{Zn}$. Appl Surf Sci. 257(3):887-898. doi:10.1016/j.apsusc.2010.07.086

37. Lu G, Bernasek SL, Schwartz J (2000) Oxidation of a polycrystalline titanium surface by oxygen and water. Surf Sci 458(1):80-90. doi:10.1016/S0039-6028(00)00420-9

38. Takadama H, Kim H-M, Kokubo T, Nakamura T (2001) An X-ray photoelectron spectroscopy study of the process of apatite formation on bioactive titanium metal. J Biomed Mater Res 55(2):185-193

39. Hanawa T, Ota M (1991) Calcium phosphate naturally formed on titanium in electrolyte solution. Biomaterials 12(8):767-774. doi:10.1016/0142-9612(91)90028-9

40. Biesinger MC, Payne BP, Grosvenor AP, Lau LWM, Gerson AR, Smart RSC (2011) Resolving surface chemical states in XPS analysis of first row transition metals, oxides and hydroxides: $\mathrm{Cr}$, Mn, Fe, Co and Ni. Appl Surf Sci. 257(7):2717-2730. doi:10. 1016/j.apsusc.2010.10.051

41. Hanawa T, Hiromoto S, Asami K (2001) Characterization of the surface oxide film of a Co-Cr-Mo alloy after being located in quasi-biological environments using XPS. Appl Surf Sci 183(1-2):68-75. doi:10.1016/S0169-4332(01)00551-7

42. Cheng X, Roscoe SG (2005) Corrosion behavior of titanium in the presence of calcium phosphate and serum proteins. Biomaterials 26(35):7350-7356. doi:10.1016/j.biomaterials.2005.05.047

43. Yan Y, Yang H, Su Y, Qiao L (2015) Albumin adsorption on CoCrMo alloy surfaces. Sci Rep. 5:18403. doi:10.1038/ srep18403 
44. Scendo M, Uznanska J (2011) The effect of ionic liquids on the corrosion inhibition of copper in acidic chloride solutions. Int $\mathbf{J}$ Corros. doi:10.1155/2011/718626

45. Yousefi A, Javadian S, Dalir N, Kakemam J, Akbari J (2015) Imidazolium-based ionic liquids as modulators of corrosion inhibition of SDS on mild steel in hydrochloric acid solutions: experimental and theoretical studies. RSC Adv. 5(16):11697-11713. doi:10.1039/C4RA10995C

46. Zheng X, Zhang S, Li W, Gong M, Yin L (2015) Experimental and theoretical studies of two imidazolium-based ionic liquids as inhibitors for mild steel in sulfuric acid solution. Corros Sci 95:168-179. doi:10.1016/j.corsci.2015.03.012

47. Dariva CG, Galio AF (2014) Corrosion inhibitors-principles, mechanisms and applications. In: Aliofkhazraei M (ed) Developments in corrosion protection, 1st edn. InTech, Rijeka, pp 365-379. doi:10.5772/57255

48. Zhou T, Xu G (2015) Aggregation behavior of ionic liquid-based gemini surfactants and their interaction with biomacromolecules. In: Paul BK, Moulik SP (eds) Ionic liquid-based surfactant science. Wiley, Hoboken, pp 127-149. doi:10.1002/9781118854501.ch6

49. Tanaka Y, Saito H, Tsutsumi Y, Doi H, Imai H, Hanawa T (2008) Active hydroxyl groups on surface oxide film of titanium, 316L stainless steel, and cobalt-chromium-molybdenum alloy and its effect on the immobilization of poly(ethylene glycol). Mater Trans 49(4):805-811. doi:10.2320/matertrans.MRA2007317

50. Palomar J, Lemus J, Gilarranz MA, Rodriguez JJ (2009) Adsorption of ionic liquids from aqueous effluents by activated carbon. Carbon N Y. 47(7):1846-1856. doi:10.1016/j.carbon. 2009.03.028

51. Wang Y, Shen F, Qi X (2016) A corn stalk-derived porous carbonaceous adsorbent for adsorption of ionic liquids from aqueous solution. RSC Adv. 6(39):32505-32513. doi:10.1039/C6RA06908H
52. Forsyth M, Howlett PC, Tan SK, MacFarlane DR, Birbilis N (2006) An Ionic liquid surface treatment for corrosion protection of magnesium alloy AZ31. Electrochem Solid-State Lett 9(11):B52-B55. doi:10.1149/1.2344826

53. Zhang Y, Forsyth M, Hinton B, Wallace GG (2011) Control of biodegradation of a $\mathrm{Mg}$ alloy in simulated body fluid. In: 18th international congress on marine corrosion, vol 3, pp 1813-1820

54. Kear G, Walsh FC (2005) The characteristics of a true Tafel slope. Corros Mater 30(6):S1-S4

55. Brand RA (2005) Joint contact stress: a reasonable surrogate for biological processes? Iowa Orthop J 25:82-94

56. Wang Y, Fan Y, Zhang M (2014) Comparison of stress on knee cartilage during kneeling and standing using finite element models. Med Eng Phys 36(4):439-447. doi:10.1016/j.medeng phy.2014.01.004

57. Bermúdez MD, Jiménez AE, Sanes J, Carrión FJ (2009) Ionic liquids as advanced lubricant fluids. Molecules 14(8):2888-2908. doi: $10.3390 /$ molecules 14082888

58. Milošev I, Metikoš-Huković M, Strehblow HH (2000) Passive film on orthopaedic TiAlV alloy formed in physiological solution investigated by X-ray photoelectron spectroscopy. Biomaterials 21(20):2103-2113. doi:10.1016/S0142-9612(00)00145-9

59. Rodrigues DC, Urban RM, Jacobs JJ, Gilbert JL (2009) In vivo severe corrosion and hydrogen embrittlement of retrieved modular body titanium alloy hip-implants. J Biomed Mater Res Part B Appl Biomater. 88(1):206-219. doi:10.1002/jbm.b.31171

60. Gilbert JL, Mali S, Urban RM, Silverton CD, Jacobs JJ (2012) In vivo oxide-induced stress corrosion cracking of Ti-6Al-4V in a neck-stem modular taper: emergent behavior in a new mechanism of in vivo corrosion. J Biomed Mater Res Part B Appl Biomater. 100(2):584-594. doi:10.1002/jbm.b.31943 